\title{
Molecular dynamics simulations for three-dimensional structures of orotate phosphoribosyltransferases constructed from a simplified amino acid set
}

Koichi Kato ${ }^{\dagger,+}$, Tomoki Nakayoshi ${ }^{\dagger}$, Mizuha Sato ${ }^{\dagger}$, Eiji Kurimoto ${ }^{\dagger}$, Akifumi Oda $^{*}, \dagger, \S$

†Faculty of Pharmacy, Meijo University, 150 Yagotoyama, Tempaku-ku, Nagoya, Aichi 468-8503, Japan,

Department of Pharmacy, Kinjo Gakuin University, 2-1723 Omori, Moriyama-ku, Nagoya, Aichi 463-8521, Japan,

§Institute for Protein Research, Osaka University, 3-2 Yamadaoka, Suita, Osaka 565-0871, Japan 
(a)

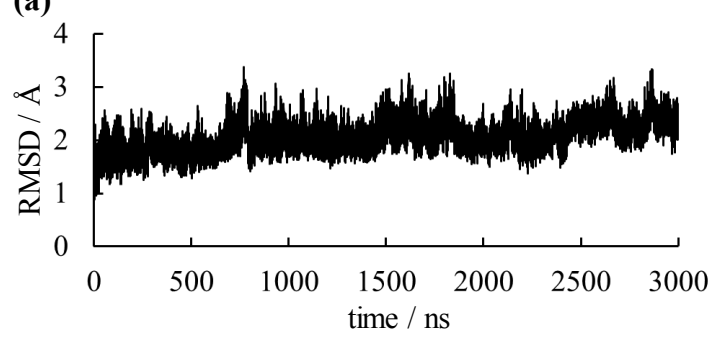

(c)

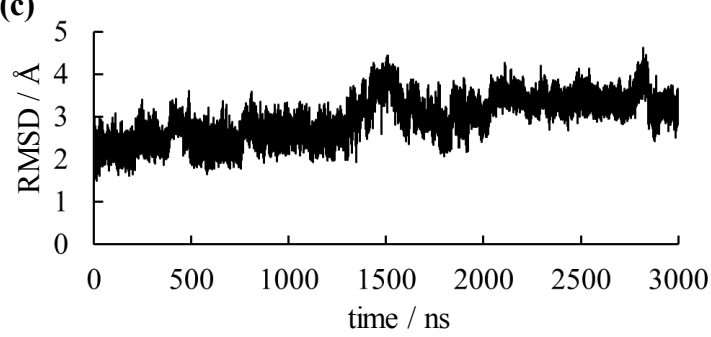

(e)

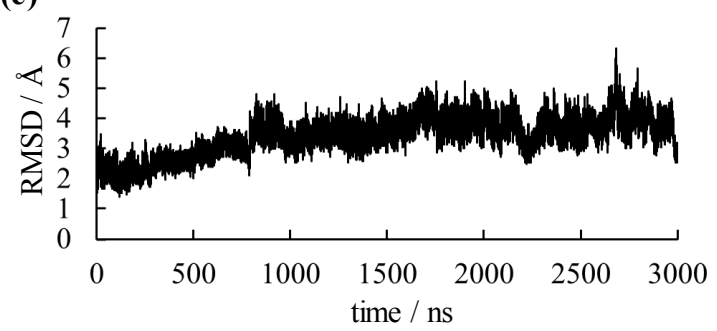

(b)

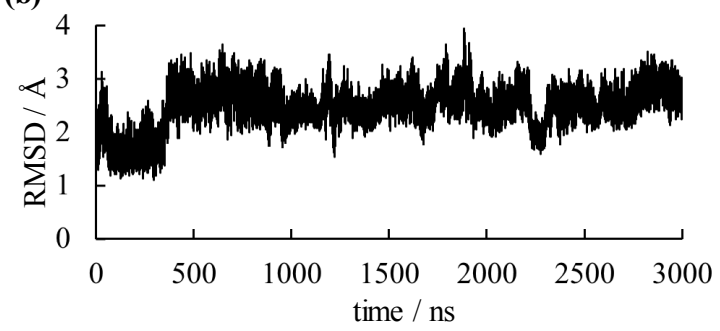

(d)

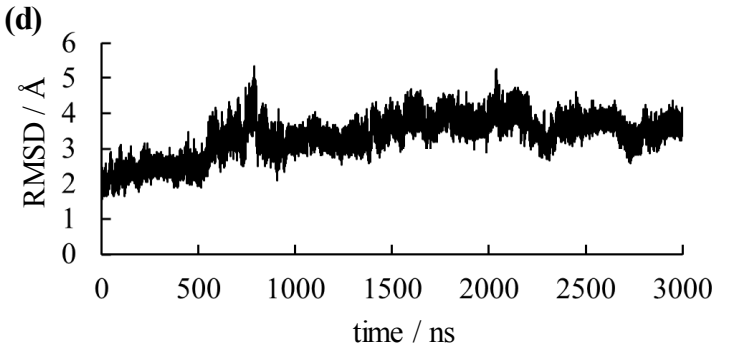

(f)

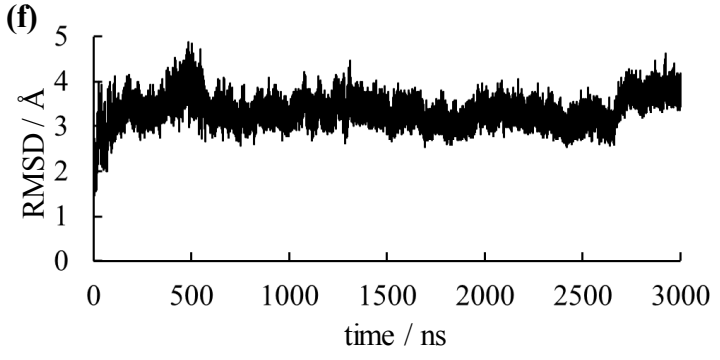

Figure S1. Root mean square deviation (RMSD) plots for the main chain atom of OPRTase monomers. RMSD plots of (a) wild-type 1, (b) wild-type 2, (c) middle-variant 1, (d) middle-variant 2, (e) Simp-2 1, and (f) Simp-2 2 in monomers. 
(a)

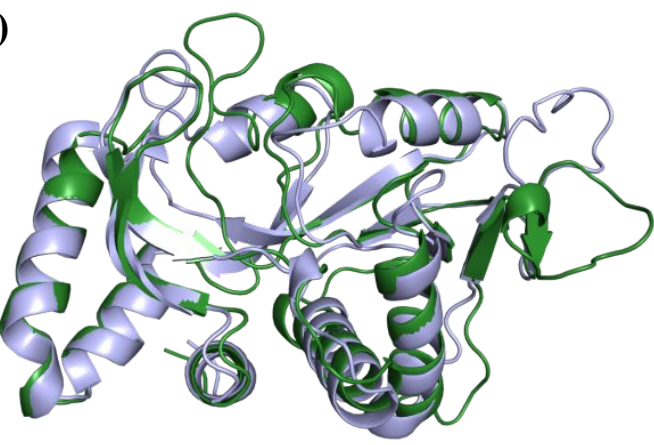

(c)

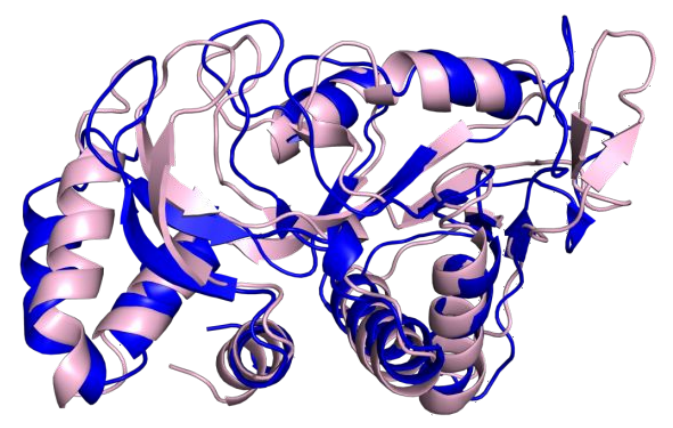

(b)

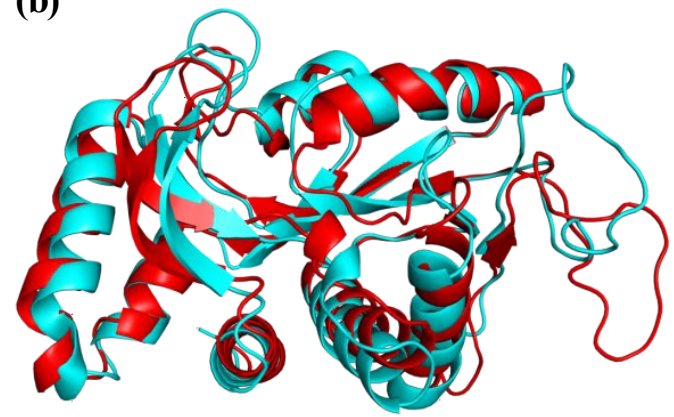

Figure S2. Comparison between the calculated monomer structures. The structural superposition of the calculated structures for (a) wild-type 1-wild-type 2, (b) middle-variant 1-middle-variant 2, and (c) Sipm-2 1-Simp-2 2. Wild-type 1: green, wild-type 2: light blue, middle variant 1: red, middle variant 2: cyan, Simp-2 1: blue, Simp-2 2: pink. 
Table S1. Secondary structure formation in $>50 \%$ of trajectories for the last $100 \mathrm{~ns}$ of simulation for the monomers

\begin{tabular}{|c|c|c|c|c|c|c|}
\hline & wild 1 & wild 2 & middle 1 & middle 2 & Simp-2 1 & Simp-2 2 \\
\hline $\mathrm{H} 1$ & $3-14$ & $3-14$ & $3-14$ & $3-14$ & $3-14$ & $3-14$ \\
\hline $\mathrm{S} 1$ & $\begin{array}{l}18-21 \\
23-24\end{array}$ & $\begin{array}{l}18-21 \\
23-24\end{array}$ & $\begin{array}{l}18-21 \\
23-24\end{array}$ & $\begin{array}{l}18-21 \\
23-24\end{array}$ & $\begin{array}{l}19-21 \\
23-24\end{array}$ & $18-20,23$ \\
\hline $\mathrm{S} 2$ & $30-35$ & $30-35$ & $30-35$ & $30-35$ & $30-34$ & $31-35$ \\
\hline $\mathrm{H} 2$ & $37-39$ & $37-39$ & $37-39$ & $37-39$ & $37-39$ & $37-39$ \\
\hline $\mathrm{H} 3$ & $43-59$ & $43-59$ & $44-59$ & $43-60$ & $43-59$ & $43-60$ \\
\hline $\mathrm{S} 3$ & $66-68$ & $66-68$ & $66-68$ & $66-69$ & $66-68$ & $66-69$ \\
\hline $\mathrm{H} 4$ & $75-89$ & $75-89$ & $75-88$ & $74-89$ & $75-88$ & $75-89$ \\
\hline $\mathrm{S} 4$ & $95-98$ & $95-98$ & $95-96$ & $95-97$ & 95 & $95-97$ \\
\hline S5 & $111-113$ & $111-113$ & not detected & 112 & $109-111$ & $112-113$ \\
\hline S6 & $119-123$ & $119-123$ & $119-123$ & $119-123$ & $119-123$ & $119-123$ \\
\hline H5 & $132-142$ & $134-142$ & $132-142$ & $\begin{array}{c}129-134 \\
137-142\end{array}$ & $133-142$ & $134-142$ \\
\hline S7 & $\begin{array}{c}146-147 \\
149-155\end{array}$ & $\begin{array}{c}146-147 \\
149-153\end{array}$ & $\begin{array}{c}146-147 \\
149-154\end{array}$ & $\begin{array}{c}146-147 \\
149-153 \\
155\end{array}$ & $\begin{array}{l}146-147 \\
149-153\end{array}$ & $\begin{array}{c}146-147 \\
149-155\end{array}$ \\
\hline H6 & $166-173$ & $168-174$ & $166-174$ & $169-173$ & $166-173$ & $167-174$ \\
\hline $\mathrm{S} 8$ & $177-183$ & 179-182 & $177-182$ & $\begin{array}{c}177-181 \\
183\end{array}$ & $\begin{array}{c}\text { 177-181 } \\
183\end{array}$ & $177-183$ \\
\hline $\mathrm{H} 7$ & 184-191 & 184-191 & 184-191 & 184-192 & 184-192 & 184-193 \\
\hline $\mathrm{H} 8$ & $195-211$ & $195-210$ & $195-210$ & $195-210$ & $198-209$ & $\begin{array}{l}195-206 \\
210-211\end{array}$ \\
\hline
\end{tabular}

H: Helix ( $\alpha$-helix and 3-10 helix ), S: para and anti $\beta$-sheet 


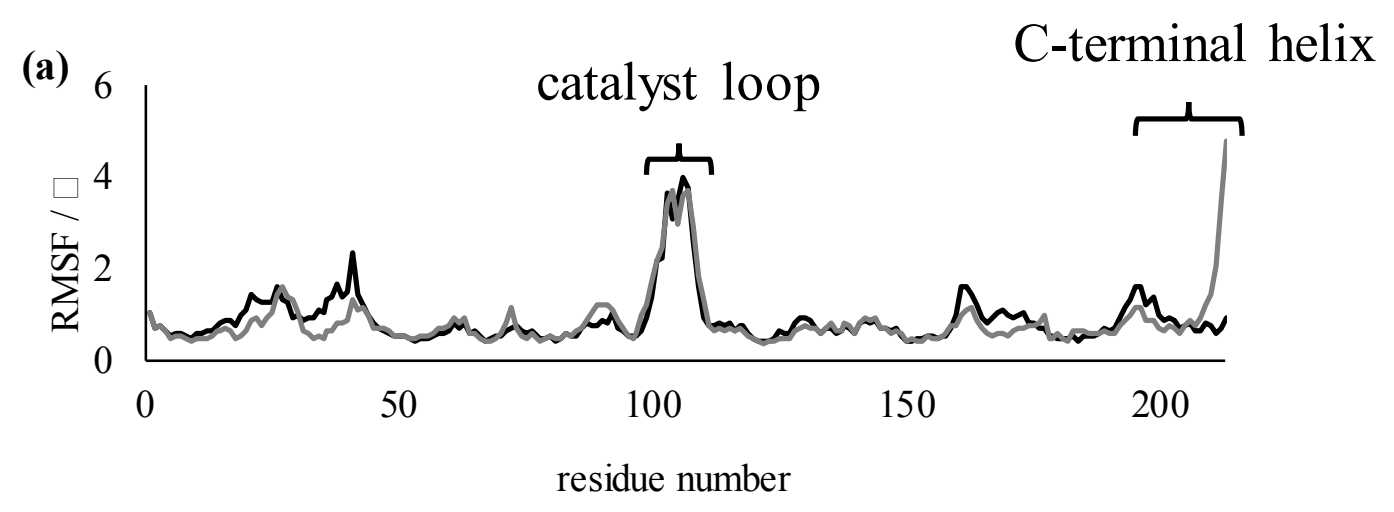

(b)

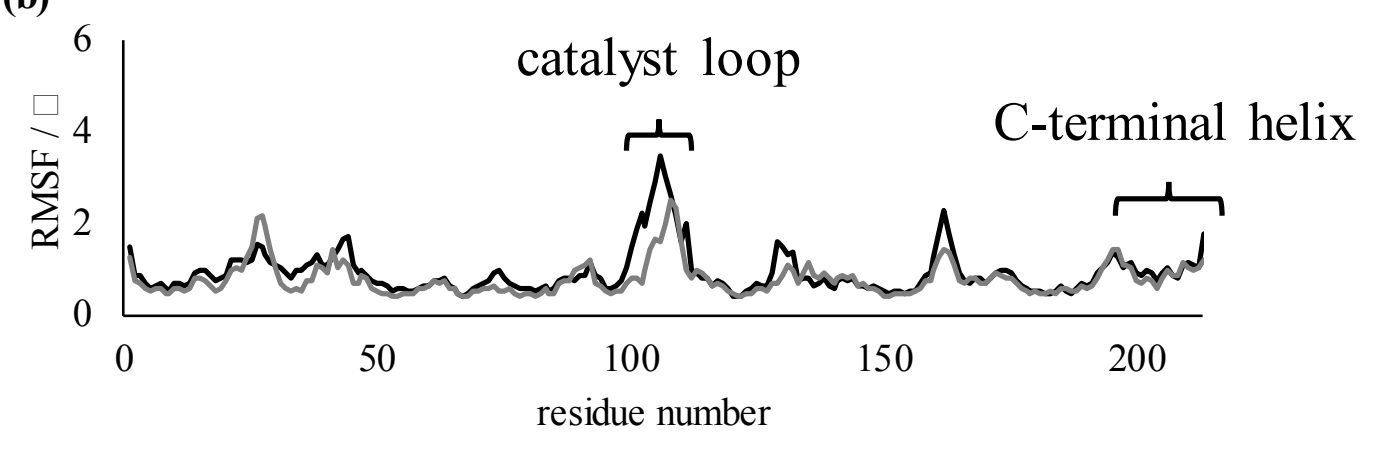

(c)

catalyst loop

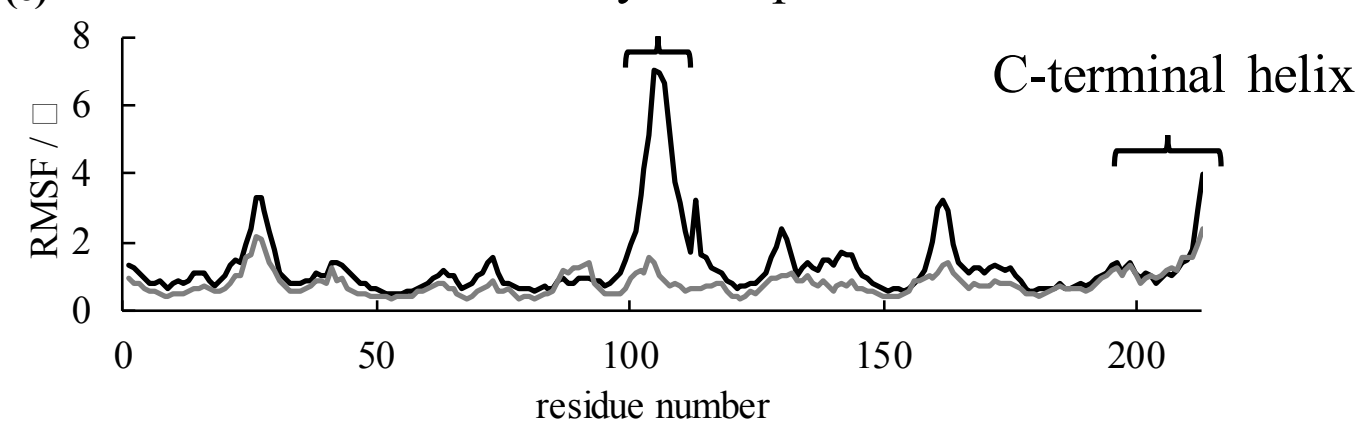

Figure S3. Comparison of root mean square fluctuations (RMSFs) between monomers 1 and

2. The RMSF plots of monomers in (a) the wild type, (b) the middle variant, and (c) Simp-2.

The plots of monomer 1 and monomer 2 are indicated by black and gray lines, respectively. 